\title{
LOS NATIVOS Y SU TERRITORIO: EL CASO DE LOS JIVARO ACHUARA EN LA AMAZONIA PERUANA
}

\author{
Luis Uriarte*
}

The aim of this article is to propose a methodology to calculate the requiered number of bectares needed by the native groups for their subsistence. Its approach is based on cological and economic considerations for establishing minimal volumes of space. The author formulates the differences between land (for slash and burn agriculture) and territory (for hunting, fishing, gathering and timber extraction). Finally, a relevant aspect of this study is the conclusion that what is currently titled is far from meeting the vital needs of the native people.

\section{xt $x$}

Le but de ce document est de proposer des instruments et une méthodologie technique pour calculer la quantité d'béctares nécessaires à la subsistence des indigènes de l'Amazonie. En se fondant sur les considérations d'ordre écologique et économique, l'auteur ćtablit le minimum des espaces nécessaires, formulant les différents concepts qui comprennent un "terrain" (pour l'borticulture rotative) et ce qui pourrait être considéré comme un "territoire" (pour la chasse, la peche, la récolte sylvestre et l'extraction forestal). Enfin, l'ouvrage prouve avec force qu'actuellement la titulation se situe bien en dessous des besoins vitaux des indigènes de l'Amazonie.

$x+x$

Der Artikel schlägt Metboden und Instrumente vor, um die Anzabl der Hektar zu bestimmen, die die ethnischen Gruppen Amazoniens für ibre Subsistenz benötigen; aufgrund von ökologischen und ökonomischen Erwägungen werden Minimal-Räume definiert. Der Autor formuliert die konzeptuellen Unterschiede im Gebrauch der Begriffe terreno, 'Land, Landstück' (für den rotativen Ackerbau), und tierra, 'Land, Lebensraum' (zum Jagen, Fischen, Sammeln und sur Holznutzung). Er kommt zu der sebr eindrucksvoll belegten Schlussfolgerung, dass das den amazonischen Indianern derzeit zugesprochene Land in keiner Weise ihre Lebensnotwendigkeiten entspricht.

* Documento de Trabajo No 2. Iquitos, 1983. 


\section{INTRODUCCION}

La titulación y posesión territorial de los grupos étnicos en el trópico siempre provoca numerosas 'fobias' y escasas 'filias', normalmente ambas desprovistas de respaldo racional documentado. La determinación de cuánta tierra suele ser doblemente emocional y arbitraria.

La finalidad de este aporte es primordialmente pragmática. Pretende documentar criterios objetivos que asistan al Estado en una mejor demarcación y titulación de territorios nativos en la Amazonía. Por ello se omitirán ciertas variables socioculturales, menos cuantificables, que podrían a ese nivel oscurecer el tema. Mi enfoque será estrictamente legal, ecológico y económico. ¿Cuánta tierra? ¿Por qué?

\section{CONTEXTO LEGAL}

1.1 El Decreto Ley 1220, denominado Tierra de Montaña, fue promulgado el 31 de Diciembre de 1909 y ha estado en vigor hasta hace nueve años. En dicha ley las tierras amazónicas eran propiedad exclusiva del Estado, quien, como dueño absoluto, adjudicaba no solo la tierra sino la mano de obra nativa. Los grupos étnicos del trópico carecían de todo derecho, pues se desconocía su existencia legal.

1.2 El 24 de Junio de 1974 se promulgó el Decreto Ley 20653 (Gobierno Velasco), donde el Estado reconoce por primera vez "la existencia legal y personalidad jurídica de las Comunidades Nativas" (Art. 6), reconoce la "tenencia y usufructo común y permanente de un mismo territorio con asentamiento nucleado o disperso" (Art. 7), "garantiza la integridad de la propiedad territorial... y otorgará títulos" (Art. 9); lá demarcación del territorio comprenderá "la superficie que actualmente ocupan (si son de carácter sedentario) y la totalidad de la superficie donde acostumbran a efectuar migraciones estacionales" (Art. 9, inc. a y b). Más aun "cuando posean tierras en cantidad insuficiente se les adjudicará el área que requieran para la satisfacción de las necesidades de la población" (Art. 9, inc. c) y se decreta que "la propiedad territorial de las Comunidades Nativas es inalienable, imprescriptible e inembargable" (Art. 11). El D.L. 20653 claramente reconoce el derecho nativo al territorio. Pero ¿cuánta tierra? La Ley (el Reglamento nunca llegó a publicarse) NO determina una cantidad específica para los grupos nativos. Sin embargo, el Cap. VII, Art. 62 y 63 habla de adjudicaciones de tierra en zonas de libre disponibilidad (i.e. las que ocupan el $98 \%$ de los grupos nativos) a favor de personas naturales (i.e. cualquier peruano). ¿Cuánta tierra? Hasta 50 Has. para cultivo y hasta 1,000 Has. para la ganadería. Cuando se trata de adjudicaciones a favor de sociedades de personas o sociedades civiles la cantidad es ampliada a 100 Has. para cultivo y 2,000 Has. para ganadería. Por su parte, la Ley 21147 promulgada el 13 de Mayo de 1975 concede contratos forestales de 1,000 Has. para pequeños extractores (Art. 31).

1.3 El 9 de Mayo de 1978 (Gobierno Morales Bermúdez) se promulga el D.L. 22175 que mantiene prácticamente idéntico el Título II referente a Comunidades Nativas (Art. 6 a 24). Al hablar de la demarcación del territorio nativo matiza lo siguiente: “ $\ldots$ cuando hayan adquirido carácter sedentario, la superficie que actualmente ocupan para poder desarrollar las actividades agropecuarias, de recolección, caza y pesca; y cuando realicen migraciones estacionales, la totalidad de la superficie 
donde se establecen al efectuarlas" (Art. 10, inc. a y b). Pero ¿cuánta tierra? Tampoco la nueva Ley, ni su Reglamento D.S. N 003-79-AA del 25 de Enero de 1979 determinan una cantidad específica de tierra para los grupos nativos. Sin embargo, el Cap. VI, Art. 63 y 64, es claro y específico. Las adjudicaciones de tierras en áreas no priorizadas para proyectos de asentamiento rural a favor de personas naturales (i.e. cualquier peruano) será de hasta 150 Has. para cultivo y hasta de 3,000 Has. para ganadería. Las 1,000 Has. para extracción forestal concedibles a cualquier pequeño extractor siguen vigentes. Las adjudicaciones a favor de sociedades de personas también son ampliadas a 1,000 Has. para cultivo y 10,000 Has. para ganadería.

1.4 El 17 de Noviembre de 1980 (Gobierno Belaúnde) se promulga el D.L. 02 de Promoción y Desarrollo Agrario. Esta Ley se aplica a toda la "actividad agraria, cualesquiera sea su forma empresarial y su ubicación en el territorio nacional" (Art. 3), "Tendrá vigencia hasta el 31 de Diciembre de 1999" (Art. 4) y donde se menciona a las Comunidades Nativas (Art. 47) por lo que se deduce que la nueva Ley las sigue reconociendo. Pero ¿cuánta tierra? Al igual que las leyes anteriores, D.L. 20653 (Velasco) y D.L. 22175 (Morales Bermúdez) no especifica nada para las adjudicaciones de territorios nativos. Pero al igual que las leyes anteriores determina la cantidad de tierra que puede adjudicarse en las áreas no priorizadas (Art. 64 que modifica el Art. 63 de la Ley 22175). A favor de personas naturales (i.e. cualquier peruano) se pueden adjudicar hasta 300 Has. para el cultivo y hasta 3,000 Has. para ganadería; y hasta 1,000 Has. para extracción forestal que siguen vigentes. Así mismo se amplían las adjudicaciones territoriales a favor de personas jurídicas nacionales: hasta 1,000 Has. para cultivo y hasta 10,000 Has. para ganadería.

1.5 En resumen, de la legislación peruana podemos destacar los elementos siguientes: Primero, el Estado reconoce claramente el derecho de las CC.NN. a un territorio y el deber del Estado a demarcarlo y titularlo. Segundo, la Ley no especifica la cantidad o extensión de dicho territorio; estipula sin embargo que se adjudique "la superficie que actualmente ocupan para desarrollar las actividades agropecuarias, de recolección, caza y pesca...", es decir, el área que usufructúan en una economía mixta e integrada practicada por todos los grupos nativos. Tercero, la Ley sí estipula cuánta tierra puede adjudicarse a cualquier persona natural y a cualquier sociedad de personas; ahora bien, el Estado reconoce a los nativos como peruanos (personas naturales) y puede reconocer las Comunidades Nativas como sociedades de personas o como personas jurídicas nacionales. Teniendo en cuenta que el Estado pretende

Adjudicación de Tierras en Zonas no priorizadas

\begin{tabular}{|c|c|c|c|c|c|c|}
\hline \multirow[b]{2}{*}{ Gobierno } & \multirow[b]{2}{*}{ Ley } & \multicolumn{3}{|c|}{$\begin{array}{c}\text { Personas Naturales } \\
\text { Cultivo Ganadería Forestal }\end{array}$} & \multicolumn{2}{|c|}{$\begin{array}{l}\text { Soc. de Personas } \\
\text { Cultivo Ganadería }\end{array}$} \\
\hline & & Has. & Has. & Has. & Has. & Has. \\
\hline Velasco & 21147 & & & 1,000 & & \\
\hline - & 20653 & 50 & 1,000 & 1,000 & 100 & 2,000 \\
\hline Morales B. & 22175 & 150 & 3,000 & 1,000 & 300 & 6,000 \\
\hline Belaúnde & 02 & 300 & 3,000 & 1,000 & 1,000 & 10,000 \\
\hline
\end{tabular}


dar un trato favorable y especial debemos asumir lógicamente que el Estado deberá adjudicar a las CC.NN. por lo menos la cantidad de tierras que puede y adjudica a otros peruanos.

De manera que cualquier persona natural, cualquier peruano puede ser adjudicatario de 1,050 Has. (D.L. 20653 de Velasco) o de 3,150 Has. (D.L. 22175 de Morales Bermúdez) o de 3,300 Has. (D.L. 02 de Belaúnde) actualmente vigente. A ello se puede añadir 1,000 Has. adicionales para extracción forestal que la Ley 21147 (aun vigente) concede a cualquier pequeño extractor. Ello equivaldría a 2,050 Has. (Ley Velasco), 4.150 Has. (Ley Morales Bermúdez) y 4,300 Has. (Ley Belaúnde).

\section{CONTEXTO ECOLOGICO}

Tanto la ecología como los estudios edafológicos concuerdan en señalar que la exhuberancia de la selva no proviene del suelo. Los suelos amazónicos (excepto en la varzea) son predominantemente distróficos, ácidos, bajos en fósforo, vulnerables a la lixiviación que drenando los nutrientes y fijando sílice y aluminio se combinan para formar arcillas semi-infecundas. $\mathrm{La}$ exhuberancia del bosque tropical proviene de un delicado y frágil equilibrio entre factores climáticos y bioecológicos. El bosque mismo convierte la energía solar, la lluvia y materia orgánica en nutrientes (carbón, nitrógeno, calcio, potasio, fósforo, etc.) que almacena principalmente en la biomasa, en suelos superficiales y en un flujo constante entre suelo, bosque, fauna y microorganismos que son reciclados y constituyen un sistema cerrado. El sistema de reciclaje es una transfusión directa de materia orgánica (humus, hojarasca) por medio de micorizas (mychoriza) a las raíces superficiales que transfieren los nutrientes, por los vasos leñosos del tronco, nuevamente a las cúpulas de hojas predominantemente escleróticas entrelazadas con plantas epifíticas. Caminar una trocha por bosque clímax es, literalmente, pasear sobre una alfombra tejida de tupidas raíces, hojarasca y microorganismos. Por otra parte el balance hídrico amazónico global depende en un estimado $68 \%$ de la evapotranspiración continental del propio bosque. Más aun, la composición heterogénea del bosque tropical húmedo (se han inventariado hasta más de 200 especies por 2 Has.) y la arquitectura poliestrada de su flora converge con otros elementos para proporcionar al bosque tropical húmedo una excepcional estabilidad y una eficiente capacidad para controlar la erosión y lixiviación.

En conclusión, la riqueza y exhuberancia del bosque tropical proviene de la biomasa eficientemente reciclada del mismo bosque. El suelo amazónico es un desierto de verde. Si desaparece el verde (biomasa) aparecerá el desierto (arcillas).

En un sistema tan frágil cualquier interferencia puede romper el equilibrio en un proceso irreversible. Ninguna imitación es como el original. Pero el sistema rotativo de tala y quema (sin dejar de ser una interferencia humana) es hasta ahora la mejor adaptación (o menor disrupción) a la dinámica ecológica del bosque amazónico. Es así mismo, la alternativa económica más viable para poblaciones de bajos recursos económicos. El rendimiento es relativamente modesto (4 toneladas por hectárea por año) pero el horticultor recoge 21 calorías por cada caloría que invierte (Huttel: 1982). Y el rendimiento es sostenible sin colapso ecológico. El sistema rotativo-de-tala-y-quema (rtq) sin embargo, para que sea sostenible sin colapso ecológico, requiere áreas suficientemente extensas para poder rotar y permitir a las 'purmas'

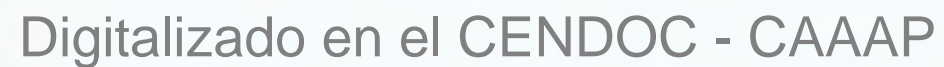


(barbecho forestal) desarrollarse hasta alcanzar el estado de bosque secundario maduro (clímax) y con ello alcanzar la regeneración de biomasa y suelo, aptos nuevamente para la tala-y-quema, cerrando el ciclo rotativo. Este período de regeneración requiere un mínimo de 25 años (Carneiro: 1961).

\section{CONTEXTO ECONOMICO}

La población "ribereña" (i.e. el campesino amazónico) en su gran mayoría y definitivamente todos los grupos nativos practican una economía fundamentalmente orientada a la subsistencia con pequeños excedentes comerciales y en el marco de una economía mixta e integrada. Es decir practican la horticultura rotativa de tala-yquema, la caza, la pesca y la recolección de flora y fauna silvestre; crecientemente empiezan a implementar la crianza de animales domésticos, especialmente gallinas y patos; chanchos en menor grado y con fricciones sociales; el ganado vacuno es prácticamente inexistente entre los grupos nativos. Esta economía mixta para que sea sostenible también requiere áreas suficientes para la regeneración de la fauna silvestre que podríamos denominar "purma animal". Este sistema económico mixto y orientado primariamente a la subsistencia es el más apropiado a las condiciones ecológicas (pluricultivo), sociales (división del trabajo) y políticas (aislamiento y marginación) de la población ribereña y nativa, en conjunto, mejor alimentada y más sana que la población urbana desempleada y hacinada en Pueblos Jóvenes.

\section{REVISION DE LAS TITULACIONES DE TIERRAS}

Habiendo esbozado el contexto legal, ecológico y económico para poder documentar ulteriormente la cantidad de tierras que debe demarcarse y titularse para las Comunidades Nativas, es conveniente analizar ahora los títulos de tierra otorgados hasta el momento. La fuente empleada para nuestro análisis es un documento publicado por el Ministerio de Agricultura, Equipo de Apoyo Técnico, del Departamento de Loreto, sede en Iquitos. La jurisdicción de dicha Dirección Regional de Agricultura abarca el $90 \%$ de los grupos nativos en la Amazonía Peruana.

4.1 El total de Comunidades Nativas tituladas con datos completos es de 185 . De las cuales 80 fueron tituladas en 1975; 51 en 1976; 13 en 1977; 13 en 1978; 3 en 1979; 25 en 1980; y ninguna en 1981, 1982 y 1983.

4.2 La cantidad de tierra titulada oscila entre $55.5 \mathrm{~m}^{2}$ por persona (sic.), 0.0055 Has/p, para la Comunidad Chayahuita de Pistón Benavides en el río Cahuapanas (título 01-1977); o $2.86 \mathrm{Has} / \mathrm{p}$ para la Comunidad Nativa Santa Rosa, ShipiboConibo, del río Pisqui (título 022-1975); hasta $196.61 \mathrm{Has} / \mathrm{p}$ para la Comunidad Orejón-Coto de San Pablo de Totolla en el río Algodón (Putumayo) (título 10-1978).

4.3 Tratando de encontrar una explicación de por qué una Comunidad Nativa recibe $0.0055 \mathrm{Has} / \mathrm{p}$ y otra Comunidad Nativa recibe $196.61 \mathrm{Has} / \mathrm{p}$, mi primera hipótesis fue que tal vez ciertos grupos habían tenido un trato privilegiado. Pero resulta que dentro de cada grupo nativo hay notorias diferencias. Así los Chayahuitas de Pistón, hemos visto, tienen 0.0055 Has/p; pero los Chayahuitas de Sábaloyacu en 
el Paranapura (título 49-1976) disfrutan de 121.33 Has/p. Los Ticuna de Cushillo Cocha (título 54-1975) tienen $3.73 \mathrm{Has} / \mathrm{p}$; mientras que los Ticuna de Bufeo Cocha (título 06-1976) disfrutan de $57.41 \mathrm{Has} / \mathrm{p}$. Los Huitoto de Pucauquillo (título 381975) en el Ampiyacu tienen 3.79 Has/p; pero los Huitoto de Esperanza en el Putumayo (título 02-1978) disfrutan de $161.46 \mathrm{Has} / \mathrm{p}$. Los Kichwa de Lagarto Cocha en el Curaray (título 15-1976) tienen 7.16 Has/p mientras que los de Ingano Llacta poseen 65.27 Has/p (título 011-1980). Finalmente (aunque podríamos continuar) los Orejon-Coto del río Algodón, vimos, poseían 196.61 Has/p mientras que sus hermanos de Puerto Huamán en el Yanayacu solamente tienen 13.11 Has/p (título 241976) (ver Tabla I).

TABLA I

Oscilación en No. de Has/p de las CC.NN. tituladas por Grupo Etnico

GRUPO ETNICO

Menor

No. de Has.

$\begin{array}{rr}30.47 & 63.66 \\ 28.86 & 143.28 \\ 50.00 & 50.00 \\ 104.09 & 104.09 \\ 7.00 & 95.00 \\ 6.99 & 33.19 \\ 112.99 & 128.23 \\ 4.11 & 35.03 \\ 14.43 & 20.42 \\ 0.0055 & 121.33 \\ 3.79 & 161.46 \\ 7.16 & 65.27 \\ 26.49 & 89.17 \\ 3.02 & 76.87 \\ 13.11 & 196.61 \\ 22.00 & 34.48 \\ 6.59 & 23.24 \\ 2.86 & 66.87 \\ 3.73 & 57.41 \\ 4.00 & 64.09 \\ 15.57 & 15.57\end{array}$

1. Achuara

2. Aguaruna

3. Arabela

4. Arahuaca (?)

5. Bora-Ocaina

6. Campa-Ashaninka

7. Candoshi S-M.

8. Cashinahua

9. Culina

10. Chayahuita

11. Huitoto/B/O

12. Kichwa Napo

13. Kichwa Pastaza

14. Piro

15. Orejón-Coto

16. Secoya

17. Sharanahua

18. Shipibo-Conibo

19. Ticuna

20. Yagua

21. Yaminahua/Amahuaca/Piro
Mayor No. de Has.

4.4 Mi segunda hipótesis fue que la ubicación de las comunidades en uno u otro río de mayor o menor interés nacional, podría explicar las notables diferencias en cuanto a la cantidad de tierra titulada. Pero encontramos que dentro de un mismo río existían contrastes significativos. Así por ejemplo en el río Paranapura hay CC.NN., como la de Pistón mencionada, que cuenta con $0.0055 \mathrm{Has} / \mathrm{p}$, pero en el mismo río está la Comunidad de Sábaloyacu que posee 121.33 Has/p (título 49. 1976). En el río Ucayali oscilan entre 3 Has/p hasta 104.09 Has/p en la Comunidad 
Arahuaca (?) de Jatitza (título 25-1976). En el río Napo las Comunidades tituladas varían entre $4 \mathrm{Has} / \mathrm{p}$ para los Yagua de Urco Miraño y $69 \mathrm{Has} / \mathrm{p}$ para los Kichwa de Puerto Elvira. El río Aguaytía oscila entre $9.43 \mathrm{Has} / \mathrm{p}$ para los Shipibo-Conibo de Sta. Rosa y en cambio los Shipibo-Conibo de Mariscal Cáceres con $66.87 \mathrm{Has} / \mathrm{p}$. En el río Urubamba la variación es de $3.02 \mathrm{Has} / \mathrm{p}$ hasta $76.87 \mathrm{Has} / \mathrm{p}$. En el Morona, de $70 \mathrm{Has} / \mathrm{p}$ hasta $175 \mathrm{Has} / \mathrm{p}$ etc. (ver Tabla II).

4.5 La tercera hipótesis fue ver si había alguna correlación entre la cantidad de tierra titulada y el año en que se tituló, que pudiera reflejar los cambios de Gobierno, cambios de legislación etc. Aparece lo siguiente: En el Gobierno Velasco (D.L. 20653), época de Sinamos, encontramos que los títulos otorgados en 1975 oscilan entre 3.01 Has/p a la Comunidad Piro de Puija en el Urubamba y 134.47 Has/p para la Comunidad Aguaruna de Pachacútec en el río Potro. Los títulos otorgados en 1976 varían también entre 4.46 Has/p para los Yagua de Basilio y 121.33 Has/p concedidos a los Chayahuitas de Sábaloyacu en el Paranapura. Los títulos otorgados en 1977 también varían entre $0.0055 \mathrm{Has} / \mathrm{p}$ ya mencionado y $161.46 \mathrm{Has} / \mathrm{p}$ concedidas a los Huitoto-Bora-Ocaina de Esperanza en el Putumayo. En el Gobierno Morales Bermúdez (D.L. 22175), época del Ministerio de Agricultura y desaparición del Sinamos, encontramos que en el año 1978 las discrepancias van desde 6.81 Has/p para los Sharanahua de San Marcos en el río Purús hasta 196.61 Has/p para los Orejón-Coto de San Pablo en el río Algodón. En el año 1979, en que solo se titularon 3 Comunidades Nativas, la variación va de 35.14 Has/p para los Chayahuitas de Bellavista en la Quebrada Supayacu a 83.53 Has/p para la Comunidad Chayahuita de Betel en la misma quebrada. En 1980 la cantidad de tierra titulada varió desde 11.91 Has/p para la Comunidad Kichwa de Oro Blanco en el río Napo, hasta 95.64 Has/p a los Bora-Ocaina de la Comunidad de Florida en el Putumayo. Finalmente en el

TABLA II

Número de Has/p de las Comunidades Tituladas segun su Ubicación

\begin{tabular}{lccc}
\hline Nombre del Río & $\begin{array}{c}\text { Menor No. } \\
\text { de Has/p }\end{array}$ & $\begin{array}{c}\text { Mayor No. } \\
\text { de Has/p }\end{array}$ & $\begin{array}{c}\text { Total CC.NN. } \\
\text { tituladas }\end{array}$ \\
\hline 1. Aguaytía & 9.43 & 66.87 & 4 \\
2. Amazonas & 3.73 & 27.00 & 5 \\
3. Ampiyacu & 3.79 & 56.76 & 5 \\
4. Cahuapana & 21.49 & 28.86 & 2 \\
5. Huasaga & 26.75 & 89.17 & 5 \\
6. Morona & 70.00 & 175.00 & 6 \\
7. Napo & 4.00 & 69.00 & 28 \\
8. Paranapura & 0.0055 & 121.33 & 13 \\
9. Pisqui & 2.86 & 25.05 & 5 \\
10. Potro-Apaga & 106.60 & 134.28 & 3 \\
11. Putumayo & 7.00 & 196.45 & 7 \\
12. Ucayali & 3.00 & 104.09 & 43 \\
13. Urubamba & 3.02 & 76.87 & 7 \\
\hline
\end{tabular}


Gobierno Belaúnde (D.L. 02) la variación es nula. Ello probablemente se debe a que en los años 1981, 1982 y 1983 no se ha titulado una sola Comunidad Nativa en el Departamento de Loreto, Región XII del Ministerio de Agricultura en Iquitos (ver Tabla III).

TABLA III

Oscilación en número de Has/p segun fecha, Gobierno y Decreto Ley

\begin{tabular}{|c|c|c|c|c|c|}
\hline Año & Gobierno & $\begin{array}{c}\text { Decreto } \\
\text { Ley }\end{array}$ & $\begin{array}{c}\text { Menor No. } \\
\text { de Has/p }\end{array}$ & $\begin{array}{c}\text { Mayor No. } \\
\text { de Has/p }\end{array}$ & $\begin{array}{c}\text { Total CC.NN. } \\
\text { tituladas }\end{array}$ \\
\hline 1975 & Velasco & 20653 & 3.01 & 134.47 & 80 \\
\hline 1976 & & 20653 & 4.46 & 121.33 & 51 \\
\hline 1977 & & 20653 & 0.0055 & 161.46 & 13 \\
\hline 1978 & Morales B. & 22175 & 6.81 & 196.61 & 13 \\
\hline 1979 & & 22175 & 35.14 & 87.53 & 3 \\
\hline 1980 & & 22175 & 11.91 & 95.64 & 25 \\
\hline 1981 & Belaúnde & 02 & - & - & 0 \\
\hline 1982 & & 02 & - & - & 0 \\
\hline 1983 & & 02 & - & - & 0 \\
\hline
\end{tabular}

4.6 Tratando de encontrar los criterios que determinaron la cantidad de Has/p de las 185 CC.NN. tituladas entre 1975 y 1983 analicé los promedios por grupo étnico. Los resultados son: Las 12 comunidades Yagua tituladas arrojan un promedio de $29.67 \mathrm{Has} / \mathrm{p}$. Las 8 comunidades Huitoto promedian $45.32 \mathrm{Has} / \mathrm{p}$. Las $36 \mathrm{comu}-$ nidades Kichwa del Napo 37.18 Has/p. Los Arabela, una sola comunidad, promedia $50 \mathrm{Has} / \mathrm{p}$. Los Bora-Ocaina, 7 comunidades Nativas, 32.32 Has/p. Las 6 comunidades Ticuna alcanzan $24.42 \mathrm{Has} / \mathrm{p}$. Los Orejón-Coto, en 2 comunidades tituladas, promedian $104.5 \mathrm{Has} / \mathrm{p}$. Las 2 comunidades Inga-Quechua del Huasaga tienen de promedio $57.83 \mathrm{Has} / \mathrm{p}$. Mientras que las 3 comunidades Achuara del mismo río promedian $41.58 \mathrm{Has} / \mathrm{p}$. Los Chayahuitas, 20 comunidades nativas, $48 \mathrm{Has} / \mathrm{p}$. Los Aguaruna, 4 comunidades nativas en el Dpto. de Loreto, disfrutan de 112.75 Has/p. Pero las 2 comunidades Candoshi-Shapra y Murato tituladas disfrutan el mayor porcentaje de tierra adjudicado a nativos, $121.11 \mathrm{Has} / \mathrm{p}$. Los Shipibo-Conibo, que cuentan con el mayor número de CC.NN. tituladas, 61, irónicamente poseen uno de los porcentajes más bajos de tierra, 15.96 Has/p. Los Piros, 6 comunidades, $20.50 \mathrm{Has} /$ p. Los (Campa) Ashaninka, 5 comunidades, 17.40 Has/p. Los Secoya, 2 comunidades, 28.24 Has/p. Los Arahuaca (?) (sic), una comunidad, 104.09 Has/p. Una comunidad de Yaminahua-Amahuaca-Piro promedia 15.57 Has/p. Los Culina, dos comunidades, 17.25 Has/p. Los Cashinahua, también dos comunidades, $19.57 \mathrm{Has} / \mathrm{p}$. Y finalmente los Sharanahua, dos comunidades, tienen el promedio más bajo, 14.92 Has/p (ver Tabla IV).

Como se puede apreciar la disparidad en la cantidad de tierra otorgada, promediando todas las CC.NN. tituladas, dentro de cada grupo étnico oscila de 14.92 


\section{TABLA IV}

Oscilación en número de Has/p de las CC.NN. Tituladas y Promedios para cada grupo segun grupos étnicos

GRUPO ETNICO

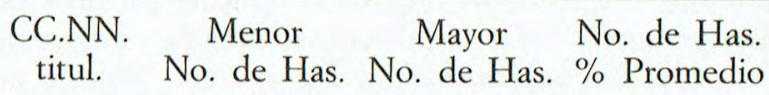

1. Achuara

2. Aguaruna

3. Arabela

4. Arahuaca (?)

5. Bora-Ocaina

6. Campa-Ashaninka

7. Candoshi S-M.

8. Cashinahua

9. Culina

10. Chayahuita

11. Huitoto/B/O

12. Kichwa Napo

13. Kichwa Pastaza

14. Piro

15. Orejón-Coto

16. Secoya

17. Sharanahua

18. Shipibo-Conibo

19. Ticuna

20. Yagua

21. Yaminahua/Amahuaca/Piro

3

4

1

1

7

5

2

2

2

20

9

36

2

6

2

2

2

61

6

12

30.47
28.86
50.00
104.09
7.00
6.99
112.99
4.11
14.43
0.0055
3.79
7.16
26.49
3.02
13.11
22.00
6.59
2.86
3.73
4.00
15.57

63.66
143.28
50.00
104.09
95.00
33.19
128.23
35.03
20.42
121.33
161.46
65.27
89.17
76.87
196.61
34.48
23.24
66.87
57.41
64.09
15.57

41.58

112.75

50.00

104.09

32.32

17.40

121.11

19.57

17.25

48.00

45.32

37.18

57.83

20.50

104.50

28.24

14.92

15.96

24.42

29.67

15.57

PROMEDIO GLOBAL GRUPOS ETNICOS:

$45.63 \mathrm{Has} / \mathrm{p}$

Has/p para los Sharanahua hasta $121.11 \mathrm{Has} / \mathrm{p}$ para los Candoshi. Y el promedio de las CC.NN. tituladas para todos los grupos étnicos es de $45.63 \mathrm{Has} / \mathrm{p}$.

4.7 De la revisión y análisis de las titulaciones hechas en el Dpto. de Loreto entre 1975 y 1983 se desprende lo siguiente:

Primero, que hay numerosas comunidades en casi todos los grupos étnicos, que no están tituladas, ni siquiera inscritas. Este es el caso especialmente de los Achuara, Candoshi Murato y Shapra, Capanahua, Matsés, etc.

Segundo, que la gran mayoría de las CC.NN. tituladas no dispone ni siquiera de "terreno" suficiente, mucho menos de "territorio" adecuado como veremos. Este es el caso especialmente de los Shipibo-Conibo, Huitoto, Piro, Ashaninka, Sharanahua, Culina, Cashinahua, Ticuna, etc.

Tercero, que no pocos de los terrenos demarcados y titulados, hoy día ya no asientan a ninguna Comunidad Nativa. Por ejemplo, la Comunidad Nativa de Pto. 
Galilea-Independencia Perú titulada para los Achuara en 1980, hoy día no asienta ningún Achuara. Este es el caso también de los Secoya del Yubineto, de Yagua en el Ampiyacu, etc. Irónicamente, pues, tendríamos lo que sucedió en una antigua ciudad de Europa: el río cambió de cauce y dejó en seco el magnífico puente romano; durante muchos años existió un "puente sin río y un río sin puente". En la Amazonía tenemos "tierras tituladas sin nativos y nativos sin tierra titulada".

Una última conclusión: No aparece (porque no parece haber existido) ningún criterio objetivo y consistente que explique la cantidad de hectáreas adjudicadas a las diferentes Comunidades Nativas, de los diferentes grupos étnicos, asentados por diferentes ríos y tituladas en diferentes años y gobiernos.

\section{EL CASO DE LOS JIVARO-ACHUARA}

Es conveniente profundizar con cierto detalle un caso concreto.

\subsection{Contexto etnográfico de los Jívaro-Achuara}

Los Jívaro-Achuara ubicados al sur del Protocolo de Río de Janeiro ocupan dispersamente una vasta región de aproximadamente $40,000 \mathrm{~km}^{2}$. El área de sus asentamientos, predominantemente interfluvial, es de transición entre selva alta y selva baja, comprendida entre 200 y 400 m.s.n.m. con una precipitación pluvial promedio aproximada de $2,800 \mathrm{~mm}$, una temperatura media de $26^{\circ} \mathrm{C}$ y con escasa variedad estacional. En la parte alta de la cuenca del río Morona los Achuara ocupan pequeños afluentes por la margen izquierda como Anasa, Sintuche, Mashumpara. La mayor concentración Achuara se encuentra en la cuenca del río Pastaza (especialmente sus afluentes de la margen derecha, Changuap o Huasaga, Manchár y Makí o Huituyacu), así como Shivín, Huagramona, Titiyacu y Tunigrama en el Alto Pastaza. Hacia el este, los Achuara se extienden por la cuenca del Alto río Corrientes (concentrados particularmente en Macusari y Paantamentsa), donde algunas fuentes imprecisamente los clasifican como Maynas (Harner 1972:12) y vulgarmente en Perú se les conoce como Jívaros. Hay un número indeterminado de Achuara amalgamados con Quichua-Alama del río Tigre y Bajo Corrientes. Finalmente existe un pequeño grupo de familias Achuara en los "zoológicos humanos", anexos a los albergues turísticos de Iquitos.

La población total Achuara, al sur del Protocolo de Río, asciende a 3,800-4,000 (Uriarte 1981), de los cuales el $63.39 \%$ se encuentra en la cuenca del Pastaza.

La población Achuara no conforma una sociedad con organización socio-política global, ni grupos corporativos de parentesco que la unifiquen. La difusa cohesión macro-achuara (aparte del lenguaje, cosmovisión y rasgos culturales compartidos) proviene de vínculos de consanguineidad y afinidad que entrelazan los dispersos grupos locales - donde realmente sí existe identidad de grupo, alianza política y unidad socio-económica - formando una compleja red de parentesco, con relaciones bilaterales, énfasis matrilateral, matrimonio de primo cruzado, poliginia sororal preferida, levirato e intercambio de hermanas y matrimonios sucesivos. La residencia es claramente matrilocal, aunque no necesariamente permanente (Harner 1972:221). Casas ovaladas, espaciosas $(15-25 \mathrm{~m} \times 8-14 \mathrm{~m})$ con cerco de guerra, multifamiliares 


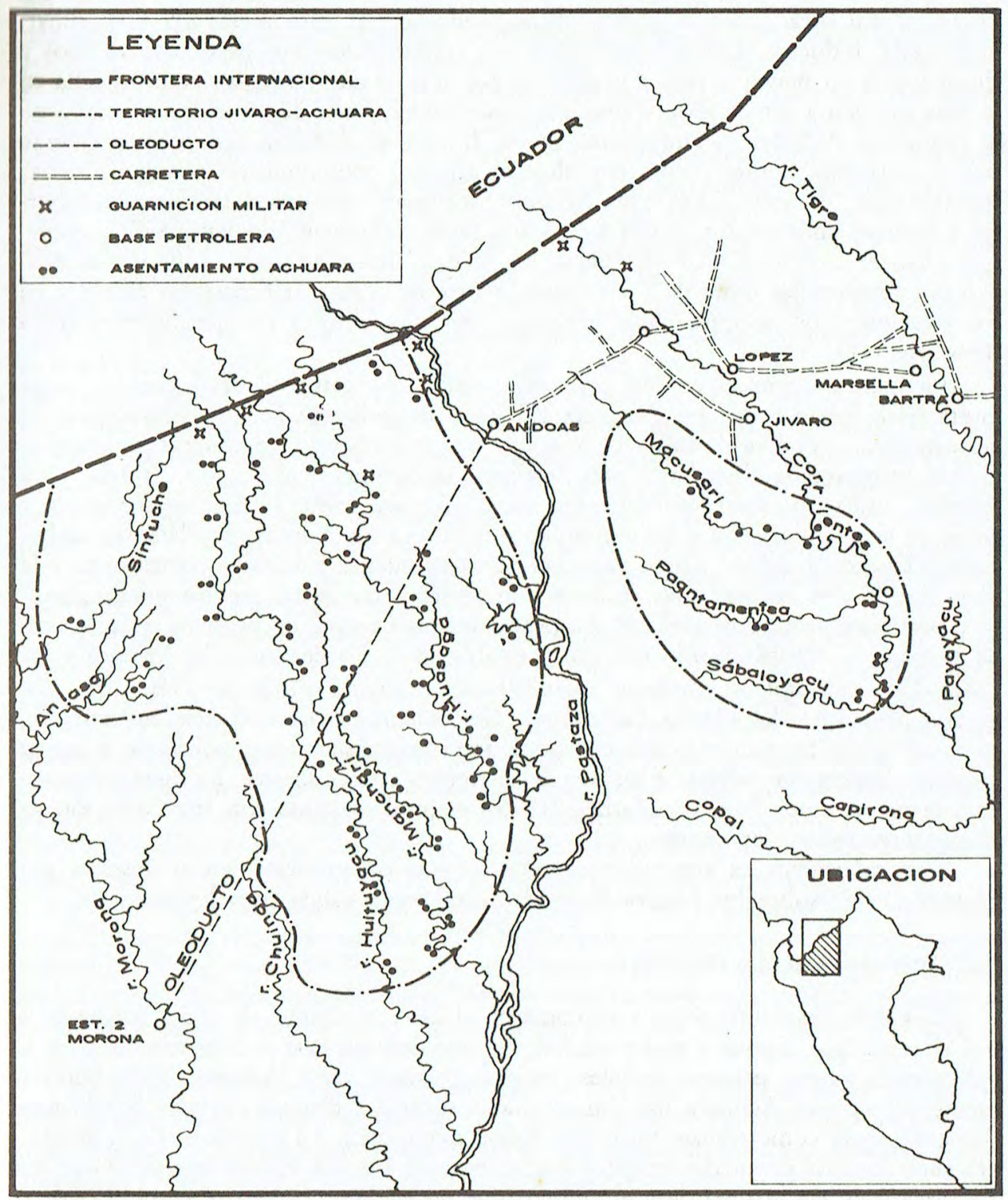

TEREITORIO JIVARO-ACHUARA DE LA AMAZONIA PERUANA 
(dos a seis familias), todavía abundan en el Manchari e igualmente en zonas del Huasaga. En otras cuencas hidrográficas predomina la casa mestizada unifamiliar, emponada, reducida. Los asentamientos más tradicionales, por estar más aislados y dispersos, tener mayor acceso a proteína y por la inversión (energía-tiempo) hecha en la casa tienden a ser considerablemente más estables, hasta 12-15 años. Sin embargo la población Achuara es sumamente móvil, fluye y se desplaza casi constantemente por el territorio, donde cuenta con alianzas afines o consanguíneas y/o con alianzas formalizadas "Amicchi". Entre los Achuara "irástasan" (pasear-visitar) para transportar y recoger información, enviar avisos/amenazas ("chícham andúkatñuka") y reafirmar alianzas es crucial. Por otra parte, los "ténak" (campamentos) donde se desplazan por temporadas hasta de 2 a 3 meses, aparte de ocasionar constantes cambios en los asentamientos, asegura alivio ecológico por una parte y enriquecimiento en la dieta por otra.

Ocupan y explotan en una economía mixta los "centros" del monte - zona interfluvial, 'tierra firme' - (Meggers 1971:14) dependiendo para su subsistencia de la horticultura rotativa de tala y quema, con un promedio de 3.6 chacras por esposa, lo cual proporciona abundante yuca destinada íntegramente al "buítsa" (tinaja) para 'masato', utilizado como el "lubricante social" (Brown 1980: 170) en mayor grado y emoción en comparación a los Aguaruna e incluso a los Napuruna. Plátanos, sachapapa (Dioscorea trifica) y gran variedad de otras plantas y frutales contribuyen a la dieta. La caza es normalmente solitaria y masculina; una de las esposas puede gustosa y periódicamente acompañarle. La pesca, segunda fuente de proteína, es practicada por todos, contribuyendo especial y establemente los ancianos, las jóvenes y los niños. Esporádicamente emplean "másu" (huaca o 'tolombo') (Tovar 1966: 103) (Aegiphila peruviana del género Clibadium). Pescas con barbasco (Clibadium strigillosum) son poco frecuentes y sólo en época de vaciante, siempre envolviendo a mayor número de personas adultas e incluso de diferentes grupos locales. La dieta, semejante a la descrita por Berlin y Markell (1976), es implementada con la recolección de abundantes frutos, larvas, etc.

Particularmente el sistema interpretativo y la organización social descrita por Harner (1972) sobre los Shuara es fundamentalmente válida para los Achuara.

\subsection{Terreno, tierra y territorio}

Los Achuara usufructúan y explotan en el sistema rotativo de tala-y-quema de 3 a 4 chacras (por esposa o mujer adulta), las que dedican casi exclusivamente para la subsistencia (yuca, plátano, frutales, barbasco, huaca, etc.). Además, y en número creciente, algunos Achuara han comenzado a rozar 1-2 chacras cuyo propósito fundamental es la comercialización (maíz, frejol, maní, etc.). La extensión de cada chacra varía, pero el promedio es aproximadamente de 1/2 Ha. Ello quiere decir que los Achuara usan un terreno para el cultivo (que en adelante designaré como $\mathrm{T}_{1}$ ) de 3 Has. por esposa o mujer adulta. De ese terreno dedican 2 Has. para la subsistencia (que en adelante designaré $\mathrm{T}_{1} \mathrm{~S}$ ) y $1 \mathrm{Ha}$. para la comercialización (que en adelante designaré $\mathrm{T}_{1} \mathrm{C}$ ). Estos terrenos están alrededor y cercanos (máximo 1/2 hora de distancia) al asentamiento.

Los Achuara, además del terreno indicado para el cultivo $\left(T_{1}\right)$, usufructúan y explotan un área de tierra para la caza, pesca, recolección y extracción forestal den- 
tro de una economía mixta. Esa área de tierra en adelante la designaré $\left(\mathrm{T}_{2}\right)$ y comprende tres zonas $(Z)$. Una primera, que podríamos llamar "intensiva" (ZI) donde efectúan una explotación de sus recursos diaria e intensa. La (ZI) se extiende en forma normalmente elíptica desde el epicentro del asentamiento hasta unas dos horas de trocha mitayera, es decir aproximadamente $4 \mathrm{~km}$ de radio. Seguidamente viene otra zona que podríamos llamar "esporádica" (ZE), pero que explotan periódicamente, es decir cada 15 días aproximadamente y se extiende también en forma elíptica hasta un radio de 4 horas de trocha mitayera, aproximadamente $7-8 \mathrm{~km}$. En la (ZE) empiezan a aparecer los primeros "ténak" o campamentos de caza (CC) con casatambo, chacra, etc. donde periódicamente se trasladan y pernoctan de una a tres noches. Finalmente usufructúan una tercera zona que podríamos llamar de "reserva" (ZR). Esta zona se explota sólo estacionalmente, normalmente dos veces al año. En la actualidad, quizá por coincidencia con las vacaciones escolares, pero sobre todo por razones ecológicas, en los meses de Enero-Febrero (máxima vaciante de los ríos) y en Julio (máxima creciente). En la (ZR) se encuentran ubicados la mayoría de los "ténak" (CC) donde estacionalmente se traslada la familia o familias por temporadas de dos a tres semanas; y no son infrecuentes estadías de uno a dos meses, particularmente cuando se dedican a la explotación forestal. La (ZR) se extiende aproximadamente hasta $9-10 \mathrm{~km}$ de radio. Más aun, esta zona sirve no solamente de "reserva") (purma animal) sino de "amortiguación social" (espacios libres) entre grupos locales heterogéneos, posiblemente enemigos (Fig. 1 y 2, p. 52).

Vemos por tanto que los asentamientos Achuara usufructúan y explotan racionalmente un territorio $(\mathrm{T})$ que abarca un terreno $\left(\mathrm{T}_{1}\right)$ dedicado a la horticultura rotativa, parte dedicada a la subsistencia $\left(\mathrm{T}_{1} \mathrm{~S}\right)$, parte dedicada a la comercialización $\left(T_{1} C\right)$. Este terreno $\left(T_{1}\right)$ les proporciona abundantes calorías 3,356 Kcal. (Berlin \& Markell 1976), escasas proteínas (roedores en las purmas, pequeñas aves, iguanas, etc.) y modestos ingresos (venta reducida de maíz, frejol, maní, animales domésticos). El territorio $(\mathrm{T})$ sin embargo, hemos visto, contiene además un área de tierra $\left(\mathrm{T}_{2}\right)$ dedicada a la caza, pesca, recolección silvestre y explotación forestal. De la primera zona, intensiva (ZI), extraen limitadas proteínas (particularmente provenientes de la pesca), materiales de construcción, chonta, aguaje, etc. De la segunda zona, esporádica (ZE), extraen proteínas suficientes, maderas valiosas para canoas y utensilios domésticos, resinas, miel, etc. La tercera zona, reserva (ZR), les proporciona abundantes proteínas, maderas comerciables, alivio ecológico (despensa de flora y fauna) y espacios de amortiguación social indispensables entre los Jívaro (Mapa 1, p. 54).

El terreno $\left(\mathrm{T}_{1}\right)$ que explotan y usufructúan está en función de la(s) esposa(s) o mujer adulta. Ahora bien, ese terreno $\left(\mathrm{T}_{1}\right)$ es explotado según el sistema rotativo de tala y quema, ecológica y económicamente el más adaptado tal como señalamos. Asi mismo, el período de purma $(\mathrm{P})$ que requiere la regeneración del bosque es, mínimo, de 25 años. Ello quiere decir que las 2-3 Has. de terreno que en la actualidad está explotando cada esposa o mujer adulta, deben multiplicarse por 25 para que la horticultura rotativa sea sostenible, sin colapso ecológico. Con ello tendríamos que cada esposa necesita y de hecho usufructúa durante una generación entre 50 y 75 Has. para cultivo. Más aun, los suelos del trópico, como vimos, son pobres (fuera de la varzea) y existen áreas (aguajales, zonas inundables - tahuampas - gradientes de $50 \%$ y más, etc.) que son totalmente inservibles para la horticultura. Por lo tanto, al 
FIO. 1 -

\section{ESQUEMA DEL TERRITORIO ASENTAMIENTO RUEINA (RIO HUASAGA)}

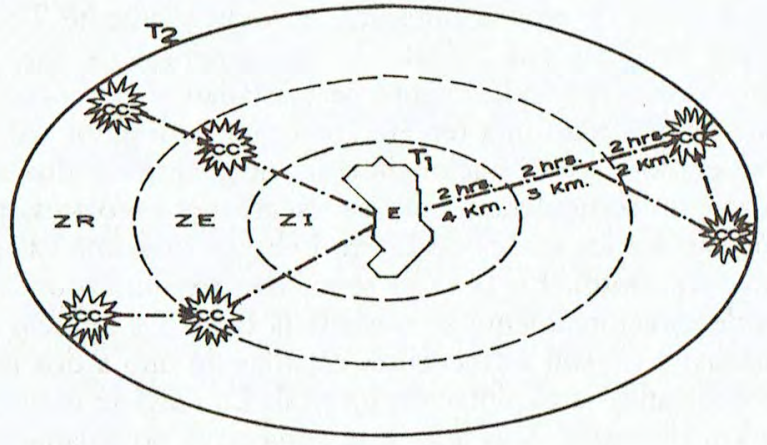

FIO. 2- ESQUEMA DE TERRITORIOS DE ASENTAMIENTOS ACHUARA

$Y$ ZONAS DE RESERVA-AMORTIGUACION SOCIAL

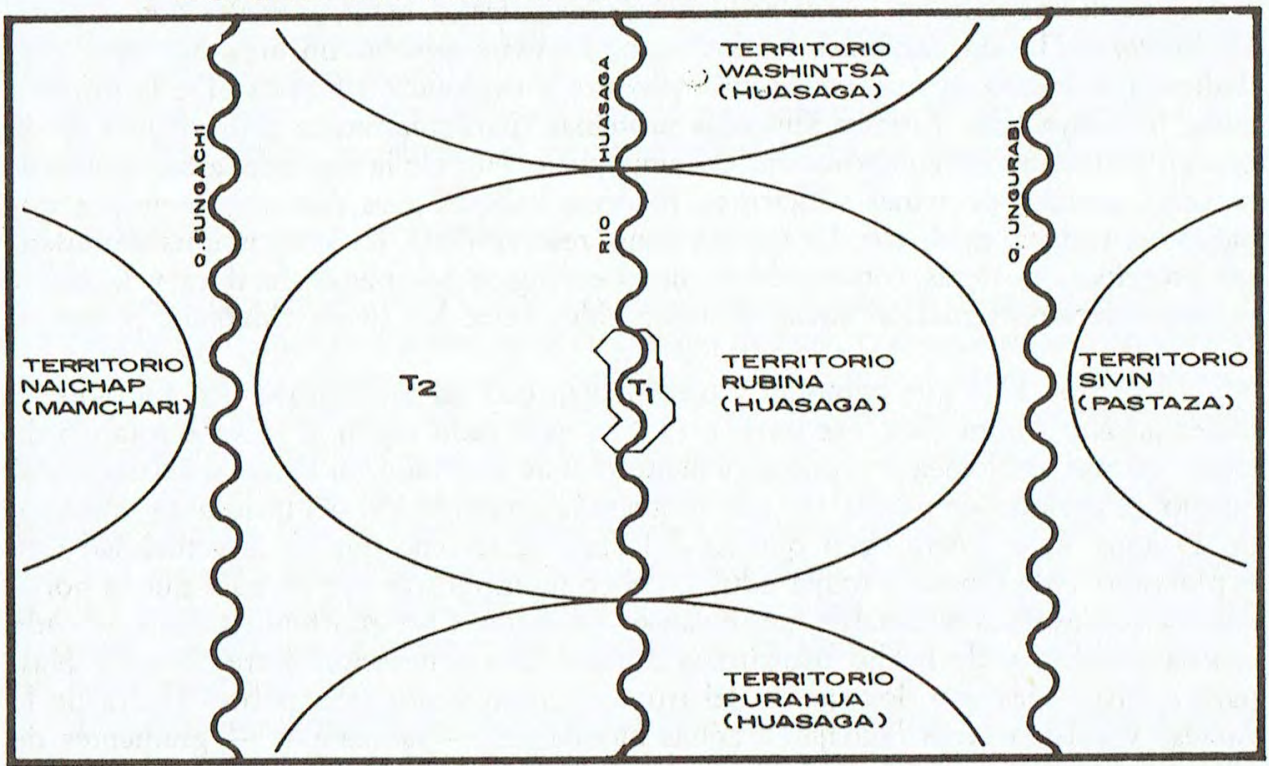

Digitalizado en el CENDOC - CAAAP 
calcular el terreno hay que incluir un coeficiente de selección (S) cuya proporción es del orden de 2:1, hasta de 5:1 según las zonas. Optando por el mínimo de 2:1 tendríamos entonces que el terreno $\left(T_{1}\right)$ necesario en el sistema rotativo y usufructuado selectivamente deberá ser como mínimo, de 100 a 150 Has. por esposa o mujer adulta. La fórmula para calcular la cantidad de terreno $\left(T_{1}\right)$ por esposa o mujer adulta es la siguiente:

$$
\mathrm{T}_{1}=\left[\left(\mathrm{T}_{1} \mathrm{~S}+\mathrm{T}_{1} \mathrm{C}\right) \times \mathrm{P} \times \mathrm{S}\right] \times \mathrm{MA}
$$

$\mathrm{T}_{1} \mathrm{~S}=2$ Has. (terreno para subsistencia)

$\mathrm{T}_{1} \mathrm{C}=1 \mathrm{Ha}$. (terreno para comercialización)

$\mathrm{P}=25$ años (purma o período de regeneración del bosque)

$\mathrm{S} \quad=2$ (selección de terreno apto para cultivo)

$\mathrm{MA}=$ Mujer adulta

Por tanto, la unidad mínima de terreno es:

$$
\mathrm{T}_{1}=[(2+1) \times 25 \times 2] \times 1=150 \mathrm{Has} / \mathrm{MA}
$$

Consecuentemente, el terreno (no el territorio, no la tierra) de un asentamiento (TA) será simplemente multiplicar el número de esposas o mujeres adultas (MA) por 150 Has.

Por otra parte, la tierra $\left(\mathrm{T}_{2}\right)$ que explotan y usufructúan está en función del esposo u hombre adulto (HA). De cada asentamiento suelen partir no más de 3-5 trochas, pero a cierta distancia (variable entre la ZI y la ZE) cada mitayero tiene su trocha. Ahora bien, la trocha mitayera hasta llegar a los últimos ténak (CC) y el límite de la ZR es de aproximadamente $9.10 \mathrm{~km}$ de la cual se desvían rastreando animales unos $250 \mathrm{~m}$ promedio por ambos lados, i.e. $500 \mathrm{~m}$. Ello equivale a 4.5-5 $\mathrm{km}^{2}$, es decir, entre 450 y 500 Has. por hombre adulto.

La fórmula para calcular la tierra $\left(\mathrm{T}_{2}\right)$ por hombre adulto $(\mathrm{HA})$ es la siguiente:

$$
\begin{gathered}
\mathrm{T}_{2}=(\mathrm{ZI}+\mathrm{ZE}+\mathrm{ZR}) \times 0.5 \mathrm{~km} \\
\mathrm{ZI}=4 \mathrm{~km} \\
\mathrm{ZE}=3 \mathrm{~km} \\
\mathrm{ZR}=3 \mathrm{~km}
\end{gathered}
$$

Substituyendo tendríamos:

$$
\mathrm{T}_{2}=(4+3+3) \times 0.5=5 \mathrm{~km}^{2}=500 \mathrm{Has} / \mathrm{HA}
$$

Consecuentemente, la tierra (no el territorio, no el terreno) de un asentamiento se calculará simplemente multiplicando el número de hombres adultos por 500 Has.

Según lo anteriormente expuesto se deduce que territorio es la suma de terreno $\left(\mathrm{T}_{1}\right)$ más tierra $\left(\mathrm{T}_{2}\right)$ (Mapa 1, p. 54). 


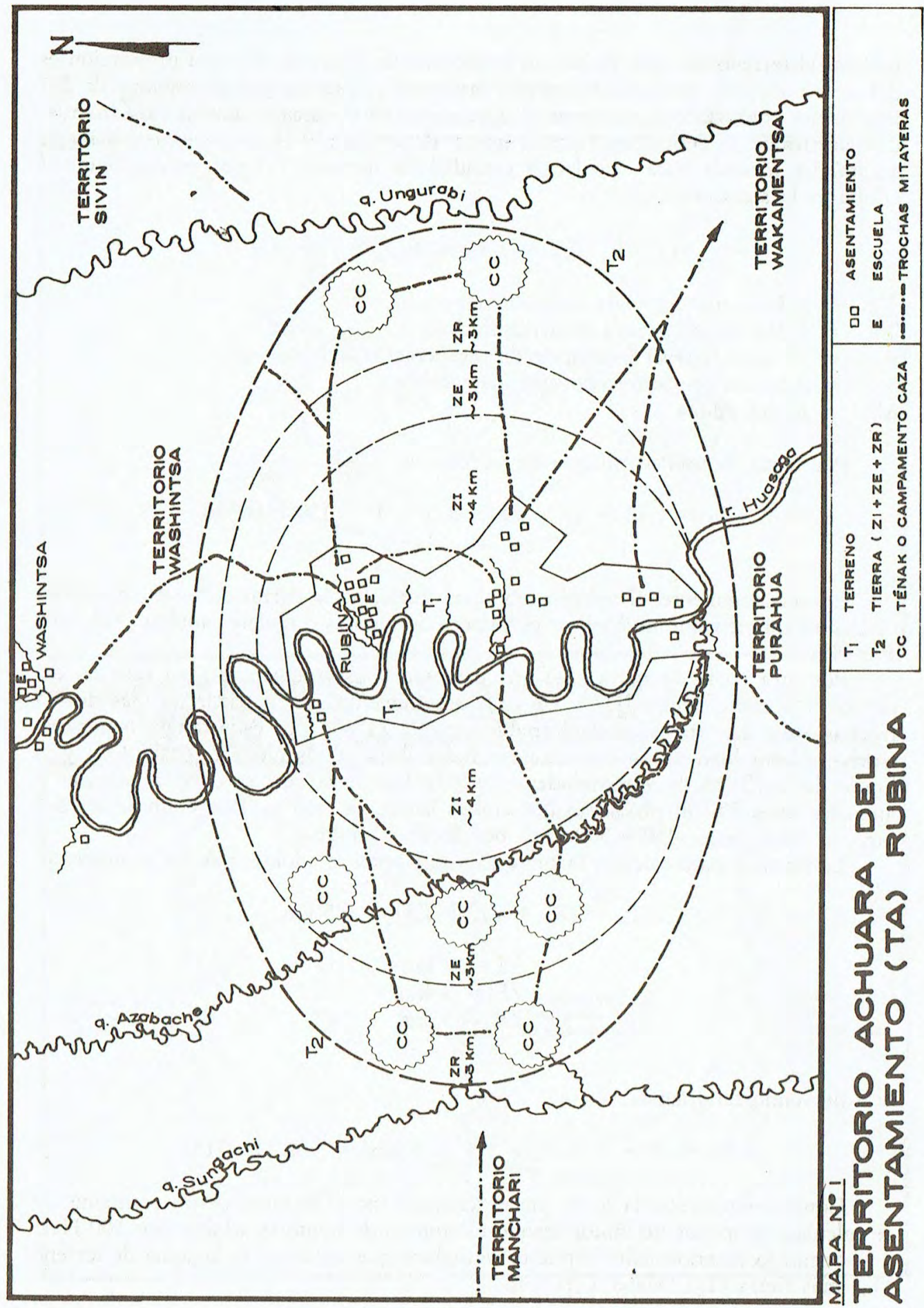


La fórmula para calcular el territorio familiar (TF), mínimo, cuando se trata de familia nuclear monógama (fnm), es:

$$
\mathrm{TF}=\mathrm{T}_{1}+\mathrm{T}_{2}
$$

donde, substituyendo tendríamos:

$$
\mathrm{T}_{1}=150 \text { Has. }+500 \text { Has. }=650 \mathrm{Has} / \mathrm{fnm}
$$

La fórmula para calcular el territorio de un asentamiento (TA) será por tanto simplemente:

$$
\mathrm{TA}=\left(\mathrm{T}_{1} \times \mathrm{MA}\right)+\left(\mathrm{T}_{2} \times \mathrm{HA}\right)
$$

donde tendríamos que substituir:

$\mathrm{T}_{1}=150$ Has.

MA = Número de mujeres adultas del asentamiento que arroje el censo demográfico.

$\mathrm{T}_{2}=500$ Has.

HA = Número de hombres adultos del asentamiento que arroje el censo demográfico.

$\mathrm{TA}=(150 \times \mathrm{MA})+(500 \times \mathrm{HA})$

Antes de proseguir con el razonamiento debo enfatizar dos observaciones. Primera, la cantidad de territorio mínimo que se deduce de la documentación anterior, es de $650 \mathrm{Has} / \mathrm{fnm}$ i.e. aproximadamente $110 \mathrm{Has} / \mathrm{p}$ (el promedio familiar entre los Achuara del Huasaga es de 5.9), cifra notablemente inferior a la cantidad que la Ley concede y adjudica a cualquier persona natural (cualquier peruano) en zonas no priorizadas que, como vimos, era de 300 Has. para cultivo, más 3,000 Has. para ganadería y 1,000 Has. para extracción forestal. La segunda observación es que, de acuerdo a los datos y razonamiento aquí presentados, también se deduce que las titulaciones anteriormente hechas no solo no demarcaron territorios suficientes para las Comunidades Nativas, sino que ni siquiera demarcaron terrenos adecuados (45.63 $\mathrm{Has} / \mathrm{p})$.

\section{3 ¿Territorio familiar, del asentamiento o} del grupo étnico?

$\mathrm{Al}$ tratar este punto es pertinente evocar nuevamente "aquel puente sin río". El territorio familiar (TF) es indiscutiblemente el menos estable. El territorio de asentamiento (TA) es relativamente menos inestable. El territorio de un grupo étnico (TE) (e incluso un segmento del mismo que abarque varios asentamientos contiguos) es, en circunstancias ordinarias, prácticamente constante. La composición demográfica cambiará considerablemente dentro de los asentamientos; los asentamientos mismos, en menor grado, sufrirán transformaciones parciales, incluso reubicación total; pero tanto el flujo demográfico como el cambio de asentamientos se circunscriben al terri- 
torio étnico que se mantiene, repito en circunstancias normales, prácticamente estable, es decir permanente. El río puede y cambiará su cauce, pero normalmente dentro del mismo valle. Para ilustrar este punto revisemos brevemente el caso de los Achuara en la cuenca del río Huasaga (Mapa 2, p. 57).

Por la etnohistoria, incluso la historia y la toponimia, se puede documentar que los Achuara ocupan la región del Alto Huasaga desde hace muchas generaciones. En ese territorio étnico ubicaban y reubicaban los asentamientos tradicionales (pequeños grupos locales de aproximadamente 35-60 personas, normalmente en una sola vivienda) dispersos por toda la cuenca del río y especialmente en pequeñas quebradas. En 1964, con la llegada a la zona del Instituto Lingüístico de Verano (ILV), tuvo lugar una generalizada reubicación y una masiva concentración demográfica. Numerosos grupos locales del Alto Huasaga, Checherta, Sinchiyacu, etc. se trasladaron a Rubina donde hasta entonces solo se asentaba el grupo Kúkush con su familia extensa, aproximadamente 40 personas, bajo un mismo techo. La nuclearización de Rubina llegó a alcanzar una población de aproximadamente 550 personas, es decir el $50 \%$ de toda la población Achuara en la cuenca del Huasaga. En 1972-73 se inició la dispersión de Rubina quedando reducida a una población de aproximadamente 250 personas. En 1977, cuando Sinamos efectuó los censos para la titulación de la comunidad, su población era de 136 personas. En 1981, cuando arribamos a la zona, contaba con 67 miembros. En la actualidad (Junio 1983) la población es de 51. Los Achuara, nuevamente se han dispersado y reubicado por toda la cuenca del Huasaga. Los asentamientos se transformaron radicalmente, pero el territorio étnico ha permanecido inalterado, constante.

Otro ejemplo: En 1977, cuando Sinamos demarcó tres comunidades Achuara del Huasaga (Washintsa, Rubina y Pto. Galilea-Independencia Perú) esta última contaba con una población de 41 habitantes. Se le titularon 2,610 Has. (i.e. 63.66 Has/ p), título No. 019-1980, pero irónicamente, el mismo año que salía su título, en 1980, ya no había un solo Achuara dentro de las 2,600 Has. demarcadas. "El río dejó el puente... pero no el valle". Todos los Achuara se trasladaron fuera del territorio del asentamiento titulado (Pto. Galilea), pero todos se reubicaron dentro del territorio étnico nunca titulado (Wacamentsa, quebrada del Huasaga). Lo mismo ha sucedido con los Secoya de la comunidad titulada de San Martín, en el YubinetoPutumayo, y de otros grupos nativos que todavía disponen de un territorio étnico o de segmentos de grupos étnicos, con varios asentamientos contiguos.

De la discusión anterior se deduce que el territorio más permanente y constante es el del grupo étnico (TE), posiblemente porque puede asimilar mejor — dentro de ciertos límites - las presiones ecológicas, demográficas y socio-culturales del mismo grupo y porque la frontera interétnica opera desde dentro (i.e. desde el mismo grupo) y desde fuera (i.e. el otro bloque étnico) con mayor eficacia que un título legal o un hito en la selva. Por otra parte, si los diferentes asentamientos y grupos locales se reubican frecuente y libremente por ese territorio étnico contiguo, es claro que se aplica la definición que la Ley 22175 otorga a una Comunidad Nativa: "... tenencia y usufructo común de un mismo territorio, con asentamiento nucleado o disperso" (Art. 8). De manera que todos esos diferentes anexos o asentamientos dispersos, pero contiguos, forman una Comunidad Nativa que comparte un mismo territorio. En las titulaciones hasta ahora hechas se ha identificado Comunidad Nativa con Asentamiento o Grupo Localizado (ni siquiera "grupo local" en sentida antropológico). Y 


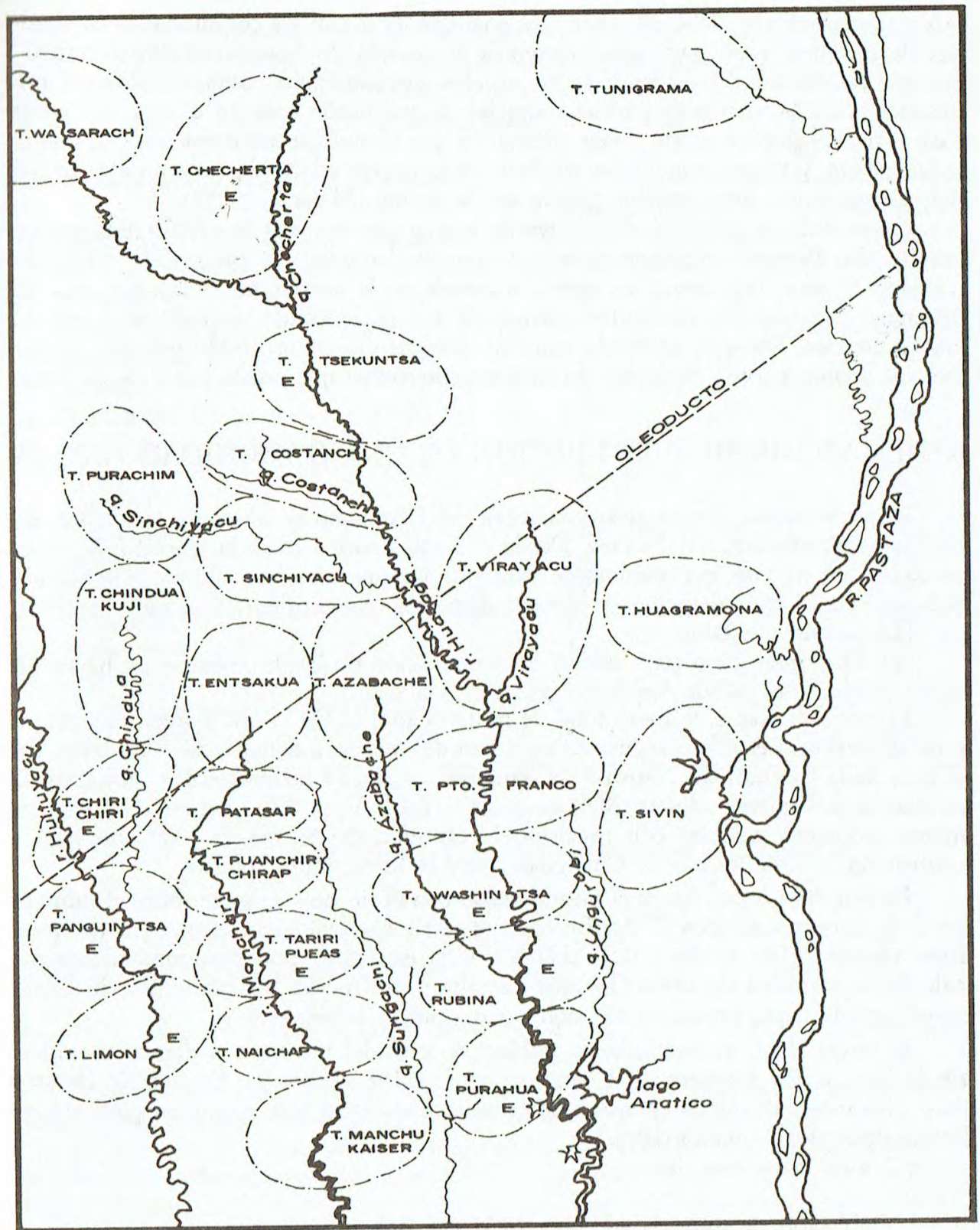

MAPA NO 2

TERRITORIOS CONTIGUOS DE LOS ASENTAMIENTOS ACHUARA.

CUENCAS MIDROORAFICAS PASTAZA, MUABAGA, MANCMARI $r$ HUITUYACU: OUE CONFIOURAN UN TERRITORIO ETNICO. 
posiblemente ello se debe en parte a la analogía legal con las comunidades campesinas de la Sierra y en parte por referencia al modelo de "caserío-ribereño-mestizo" que son totalmente diferentes. Sólo en aquellos asentamientos nativos totalmente atomizados, que forman islas étnicas rodeadas de población mestiza u otra por todas partes, parece que no existe mejor alternativa que identificar asentamiento con comunidad nativa, y consecuentemente titularle un territorio adecuado (terreno más tierra) del asentamiento, pero esto no puede ser la norma (Mapa 2, p. 57).

Como indiqué al inicio, el objetivo de este aporte era y es esencial y doblemente pragmático. Primero responde clara y documentadamente a la pregunta ¿cuánto territorio? Y ¿por qué? Segundo, asistir al Estado en la importante y urgente tarea de demarcar y titular los territorios nativos de forma adecuada, expeditiva e incluso menos costosa. Por ello pretendo concluir exponiendo de un modo práctico y concreto la demarcación y titulación de un territorio nativo que pueda servir de muestra.

\section{DEMARCACION Y TITULACION DE UNA COMUNIDAD NATIVA}

La Comunidad Nativa Jívaro-Achuara del Changuap se ubica en la cuenca del río Huasaga, afluente del Pastaza. Desde el Lago Anatico hasta la frontera Norte es un área que asienta exclusivamente (excepto las guarniciones militares) población Achuara, en 14 anexos contiguos aunque dispersos que configuran un territorio étnico (TE) común y estable.

6.1 El primer paso para iniciar la demarcación-titulación consiste en hacer un censo poblacional donde los datos cruciales son tres:

Primero, censar el número total de mujeres adultas (MA) que poseen chacras en todo el territorio étnico o segmento contiguo del mismo a demarcarse y titularse. En el caso de la Comunidad Nativa del Changuap, en sus 14 asentamientos contigúos, la población de mujeres adultas (MA) es de 243 (Tabla V, p. 59). Con ese dato simplemente, podemos calcular con precisión la cantidad de terreno $\left(T_{1}\right)$ que necesita y usufructúa la Comunidad de Changuap, para la horticultura rotativa.

En segundo lugar, hacer el mismo censo con el fin de averiguar ahora el número total de hombres adultos (HA). En todo el territorio Changuap el número de hombres adultos (HA) es de 191 (Tabla V). Con este dato podemos inmediatamente calcular la cantidad de tierra $\left(\mathrm{T}_{2}\right)$ que necesita y usufructúa la Comunidad de Changuap para la caza, pesca, recolección y explotación forestal.

El tercer dato, es averiguar la población total del territorio a demarcar-titular. En el caso de los Achuara del Changuap es de 1,198 (Tabla V). En función de este dato podemos calcular la cantidad de territorio adicional que requieren para absorber el crecimiento demográfico.

6.2 Con estos tres datos:

Población de mujeres adultas $(\mathrm{MA})=243$

Población de hombres adultos $(\mathrm{HA})=191$

$\begin{array}{ll}\text { Pobláción total } & (\mathrm{PT})=1,198\end{array}$

podemos calcular la cantidad de terreno $\left(\mathrm{T}_{1}\right)$, de tierra $\left(\mathrm{T}_{2}\right)$, de territorio $(\mathrm{T})$ y de título territorial (TT). 


\section{TABLA V \\ Población y Asentamiento Jivaro-Achuara \\ Comunidad de Changuap \\ (Rio Huasaga)}

\begin{tabular}{lrrrr}
\hline Asentamiento & $\begin{array}{c}\text { No de } \\
\text { Familias }\end{array}$ & $\begin{array}{c}\text { Población } \\
\text { Varones }\end{array}$ & $\begin{array}{c}\text { Adulta } \\
\text { Mujeres }\end{array}$ & $\begin{array}{c}\text { Habitantes } \\
\text { Total }\end{array}$ \\
\hline 1. Purahua & 26 & 24 & 34 & 163 \\
2. Azabache A. & 6 & 6 & 7 & 33 \\
3. Kasurentsa & 10 & 7 & 12 & 52 \\
4. Rubina & 13 & 10 & 15 & 67 \\
5. Washintsa & 30 & 27 & 37 & 220 \\
6. Pto. Franco & 9 & 11 & 11 & 49 \\
7. Virayacu & 6 & 4 & 8 & 29 \\
8. Montete & 6 & 7 & 7 & 31 \\
9. Azabache B. & 14 & 12 & 16 & 64 \\
10. Sanchik & 19 & 19 & 21 & 115 \\
11. Puranchin & 14 & 14 & 19 & 96 \\
12. Costanchi & 11 & 12 & 12 & 66 \\
13. Tsekuuntsa & 16 & 17 & 20 & 96 \\
14. Checherta & 20 & 21 & 24 & 117 \\
\hline \multicolumn{1}{c}{ Total } & 200 & 191 & 243 & 1,198 \\
\hline
\end{tabular}

6.2.1 Terreno $\left(\mathrm{T}_{1}\right)$ para cultivo: Como ya establecimos la fórmula es:

$$
\mathrm{T}_{1}=\left[\left(\mathrm{T}_{1} \mathrm{~S}+\mathrm{T}_{1} \mathrm{C}\right) \times \mathrm{P} \times \mathrm{S}\right]
$$

Substituyendo los valores tendríamos:

$\mathrm{T}_{1}=[(2$ Has. +1 Ha. $) \times 25$ años $\times 2] \times 243=150 \times 243=36,450$ Has.

Tenemos por tanto que el terreno mínimo que debe demarcarse para toda la Comunidad de Changuap con sus 14 anexos es de 36,450 Has.

6.2.2 Tierra $\left(\mathrm{T}_{2}\right)$ para caza, pesca, recolección y extracción forestal: Como ya establecimos la fórmula es:

$$
\mathrm{T}_{2}=[(\mathrm{ZI}+\mathrm{ZE}+\mathrm{ZR}) \times \text { arm }] \times \mathrm{HA}
$$

Substituyendo los valores tendríamos:

$$
\begin{aligned}
& \mathrm{T}_{2}=[(4 \mathrm{~km}+3 \mathrm{~km}+3 \mathrm{~km}) \times 0.5 \mathrm{~km}] \times 191= \\
& \mathrm{T}_{2}=[10 \times 0.5] \times 191=5 \mathrm{~km}^{2} \times 191
\end{aligned}
$$


Convirtiendo los $\mathrm{Km}^{2}$ a Has. $=500$ Has. $\times 191=95,500$ Has.

Tenemos por tanto que la tierra mínima que debe demarcarse para toda la Comunidad de Changuap es de 95,500 Has. tierra.

6.2.3 Territorio étnico (TE) es, como ya establecimos, la suma de terreno más

$$
\begin{gathered}
\mathrm{T}=\mathrm{T}_{1}=\mathrm{T}_{2} \\
\mathrm{TE}=36,450 \text { Has. }+95,500 \text { Has. }=131,950 \text { Has. }
\end{gathered}
$$

Tenemos por tanto que el territorio mínimo que debe demarcarse para toda la Comunidad de Changuap es de 131,950 Has.

En forma directa y simplificada, el territorio étnico (TE) también se puede calcular con la fórmula:

$$
\begin{aligned}
& \mathrm{TE}=\left(\mathrm{T}_{1} \times \mathrm{MA}\right)+\left(\mathrm{T}_{2} \times \mathrm{HA}\right)=(150 \times 243)+(500 \times 191)=36,450+95,500 \\
& =131,950 \text { Has. }
\end{aligned}
$$

6.2.4 Hasta el momento hemos pues calculado el territorio que en la actualidad usufructúa y requiere la Comunidad de Changuap. Sin embargo, a no ser que se pretenda asfixiar al grupo con estancamiento demográfico, el título territorial (TT) debe incluir territorio adicional para absorber un crecimiento demográfico al menos para una generación. Ese territorio adicional se calcula en base a la tasa del crecimiento demográfico. Según el Instituto de Planificación, la tasa de crecimiento demográfico para el Dpto. de Loreto es de 2.6. Permitiendo a los Nativos al menos una modesta tasa de crecimiento demográfico del orden de 1\%, la población Achuara del Changuap aumentaría en 12 personas/año y por tanto en una generación (25 años) apenas aumentaría 300 personas. Pues bien, concediendo esa mínima tasa de crecimiento demográfico habría que titular 33,000 Has. adicionales para poder absorber ese bajo crecimiento, es decir 110 Has. $\times 300$.

6.3 Título Territorial (TT) consecuentemente debe incluir el terreno del grupo, más la tierra del grupo (ello equivale a decir el territorio étnico actual) más el área de crecimiento demográfico (ACD), calculada en base a una tasa mínima y al menos del $1 \%$ para una generación, 25 años. La fórmula por tanto para calcular el título territorial es:

$$
\begin{aligned}
& \mathrm{TT}=\mathrm{T}_{1}+\mathrm{T}_{2}+\mathrm{ACD} \\
& \mathrm{TT}=36,450+95,500+33,000=164,950 \text { Has. }
\end{aligned}
$$

En conclusión, para la Comunidad de Changuap se deben demarcar y titular 164,950 Has. Aquí y ahora se sabe ¿cuánta tierra? ¿por qué? y ¿cómo proceder sistemática y consistentemente?

\section{4 ¿Es realmente demasiado territorio para los Nativos?}

Eri Octubre, 1981 Ordeloreto-Ministerio de Agricultura en coordinación con CRIOR y CODEA, designaron a un antropólogo del Ministerio de Agricultura en Iquitos y también un topógrafo del ministerio, en Yurimaguas, para hacer la demarcación y titulación de tierra de los Jívaro-Achuara en las cuencas hidrográficas del 


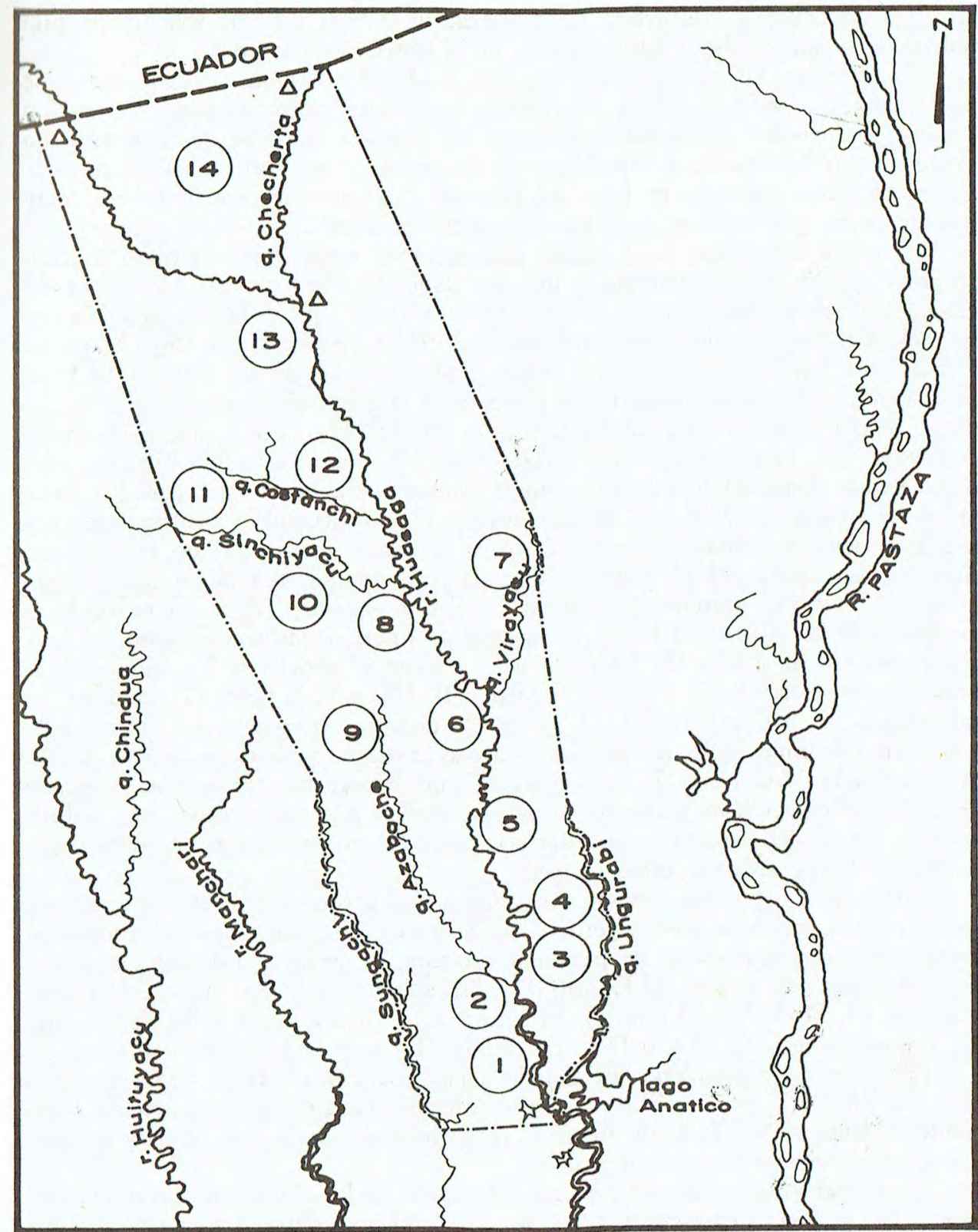

MAPA DE LA COMUNIDAD DE CHANGUAP

LEVENDA

( 7 ANEXOB. ABENTAMIENTOB ACMUARA

$\triangle$ GUaRnicion militak

TERTITOFIO ETNICO JIVARO-ACMUARA CMANOUAP. 168.D20 MOQ. 
Huasaga, Manchari y Huituyacu. La demarcación se hizo y fui no solo testigo presencial, sino qué colaboré estrechamente en el trabajo de campo.

Sin embargo, en entrevista reciente con el Director Regional del Ministerio de Agricultura, con sede en Iquitos, dos hechos aparecieron claros: Primero, del trabajo (costoso por cierto) de demarcación para los Achuara en 1981, curiosamente no existe ningún documento o expediente de titulación, ni en Yurimaguas, ni en Iquitos, ni en Lima. Segundo, en frase del Director: “... nunca se va a titular esa cantidad de tierra, por cuencas, para los nativos de esa zona".

¿Por qué no? Quizá la 'comisión multisectorial' recién formada para "unificar criterios" puede documentar algún día una respuesta. ¿Por qué sí? La cuenca del Huasaga, desde el Lago Anatico hasta la frontera Norte (que es el área ocupada por los Achuara) tiene una longitud aproximada de $94 \mathrm{~km}$ (Amer. Geogr. Soc. Map). La demarcación hecha en 1981 incluía $18 \mathrm{~km}$ promedio, $9 \mathrm{~km}$ a cada margen del Huasaga, desde la quebrada Sungachi (al oeste) hasta la quebrada Ungurabi (al este). Es decir, se demarcó un área de $1,692 \mathrm{~km}^{2}$ o 169,920 Has. Por tanto, el territorio demarcado era levemente superior (exactamente 4,970 Has.) a las 164,950 Has. que, según hemos documentado, es el territorio mínimo que debe titularse para la Comunidad de Changuap. Más aun, si descontamos el área ocupada y usufructuada por tres guarniciones militares (Yánez, Luna y E. Santo) enclavadas en el territorio Achuara, la cuenca del Huasaga demarcada sería inferior al mínimo que debiera titularse. Territorio mínimo, porque al calcular el terreno $\left(\mathrm{T}_{1}\right)$ se ha reducido la extensión de las chacras ( 3 Has.), se ha bajado el período de regeneración del bosque o período de purma (P) (algunos estiman hasta 40 años) y se ha disminuido el principio de selección a 2:1 (otros calculan 5:1). Más aun, la tierra $\left(\mathrm{T}_{2}\right)$ también ha sido reducida, pues las zonas $(\mathrm{ZI}+\mathrm{ZE}+\mathrm{ZR})$ pueden sobrepasar los $9 \mathrm{~km}$ de radio y el rastreo de animales en las trochas mitayeras se desvía ordinariamente más de 250 m a cada lado. Finalmente, la tasa de crecimiento demográfico también se ha bajado de $2.6 \%$ correspondiente a Loreto (a nivel nacional es aún más elevada) a un reducido $1 \%$, que es definitivamente inferior a la que exhiben los Achuara y posiblemente también a la que exhiben otros grupos.

Con todo es oportuno revisar nuevamente para contraste la cantidad de tierras que el Estado, según las leyes vigentes, adjudicaría en esa misma zona, no priorizada, a una población equivalente de personas naturales, es decir, a cualquier peruano.

En tierras para cultivo: El Estado (D.L. 02) adjudicaría 72,900 Has. a 243 peruanos (Art. 64, Mod. Art. 63, inc. a). El equivalente Achuara, como se ha documentado, solamente reclama 36,450 Has. de terreno $\left(T_{1}\right)$ para la horticultura rotativa.

En tierras para ganadería: El Estado adjudicaría 573,000 Has. a 191 peruanos (Art. 64, Mod. 63, inc. b). El equivalente Achuara, como se ha documentado, solamente reclama 95,500 Has. de tierra $\left(\mathrm{T}_{2}\right)$, no para ganadería pero sí para la caza, pesca, recolección y explotación forestal.

En tierras para extracción forestal: El Estado (D.L. 21147) otorgaría 191,000 Has. a 191 pequeños extractores (Art. 36, inc. a). El equivalente Achuara no reclama esta área adicional, porque usufructúa para la extracción forestal la misma tierra $\left(T_{2}\right)$ que para la caza, pesca y recolección. Requiere en cambio, solamente 33,000 Has. para absorber un modesto crecimiento demográfico (ACD).

Es pertinente entonces preguntar: ¿Por qué 36,450 Has. $\left(T_{1}\right), 95,500 \mathrm{Has} .\left(\mathrm{T}_{2}\right)$ y 33,000 Has. (ACD) para nativos se considera "excesivo"? y en cambio ¿por qué 
72,900 Has. (C), 573,000 Has. (G) y 191,000 Has. (F) para cualquier adjudicatario peruano se considera (y en realidad es) legal, apropiado y normal? Obviamente la respuesta a esa pregunta le corresponde a otros. Por mi parte, yo he tratado de responder ¿cuánto territorio se debe titular? ¿por qué? y ¿cómo determinarlo sistemática y consistentemente?

\section{CONCLUSION}

Se han considerado aspectos legales, ecológicos y económicos, para establecer el marco de referencia (posibilidades y limitaciones) en la titulación de tierras nativas. Seguidamente, un análisis de las Comunidades Nativas tituladas, puso de manifiesto la inconsistencia e insuficiencia al determinar la extensión del área a demarcarse. Así mismo reveló que todas las titulaciones han sido de asentamientos y no de territorio étnico. Consecuentemente, se establecieron límites y divisiones intra-étnicos (entre asentamientos) en lugar de fronteras inter-étnicas (entre territorios).

Sin embargo, a partir de una descripción etnográfica de los Jívaro-Achuara, se ha documentado que usufructúan un "territorio" que comprende un "terreno" (para horticultura rotativa) y un área de "tierra" (para caza, pesca, recolección silvestre y extracción forestal). Se ha analizado, así mismo, por qué los territorios étnicos tienden a ser constantes y estables, mientras que los asentamientos son fluctuantes y temporales. Igualmente, por qué la población nativa en el territorio étnico es constante, pero la composición demográfica de los asentamientos es sumamente variable.

A partir de los Jívaro-Achuara y dentro del contexto legal, ecológico y económico previamente esbozado, se ha elaborado una fórmula clara para determinar sistemática y consistentemente la extensión territorial que debe demarcarse y titularse. Dicha fórmula es aplicable también a otros grupos nativos del trópico. En base a dicha fórmula se ha determinado la cantidad mínima de 'terreno' (150 Has. por mujer adulta), de 'tierra' ( 500 Has. por hombre adulto) y finalmente se puede determinar con precisión el área adicional para absorber un modesto crecimiento demográfico. El título territorial (la suma de terreno, tierra y área de crecimiento demográfico) promedia 110 Has. por persona.

Espero haber contribuido: Primero, a desligar el problema de territorios nativos de 'fobias y filias'; segundo, a diseñar una herramienta de trabajo (una fórmula) funcional, clara y adecuada para futuras titulaciones. El resultado será un menor número de Comunidades Nativas insuficientemente tituladas, un menor número de "territorios titulados sin nativos" (puentes sin río). La inversa, "menos nativos sin tierra titulada" (ríos sin puente) obviamente seguirá siendo una opción fundamentalmente política que corresponde a otros tomar. 


\section{B I B L I O G R A F I A}

BERLIN, Elois Ann and Edward Markell 1976 Parasites and Nutrition: The dynamics of health among the Aguaruna Jivaro. MS.

BROWN, Michael F. and Margaret L. Van Bolt

1980 "Aguaruna Jivaro Gardening Magic in the Alto Rio Mayo, Peru." En: Ethnology XIX: 2, pp. 169-190. University of Michigan.

CARNEIRO, Robert L.

1961 "Slash-and-Burn Cultivation Among the Kuikuru and Its Implications for Cultural Development in the Amazon Basin." En: J. Wilbert (Ed.) The Evolution of Horticultural Systems in Native South America, Causes and Consequences: A Symposium. Antropológica, Caracas, 47-67, Supplement Publication $\mathrm{N}^{\circ} 2$.

HARNER, Michael

1972 The Jivaro: People of the sacred waterfalls. Garden City: Doubleday.
HUTTEL, Charles

1982 La arquitectura de los diferentes tipos de bosques de la Amazonía. MS.

Instituto Nacional de Planificación

1972 Plan Nacional de Desarrollo 197175, vol. XI: Políticas de Desarrollo Regional.

MEGGERS, Betty

1971 Amazonia: Man and culture in a counterfeit paradise. Chicago: Aldine-Atherton.

TOVAR, Enrique

1966 Vocabulario del Oriente Peruano. Lima: Universidad Nacional Mayor de San Marcos.

URIARTE, Luis M.

1981 Población Achuara: Documento de trabajo para titulación de tierras. Ordeloreto-Iquitos. MS. 